\title{
Structures associated with feeding in three broad-mouthed, benthic fish groups
}

\author{
William A. Gosline \\ Museum of Zoology, University of Michigan, Ann Arbor, MI 48109, U.S.A. \\ Received 28.7.1995 Accepted 26.2.1996
}

Key words: Feeding structures, Flatheads, Goosefishes, Toadfishes

\section{Synopsis}

The flatheads, toadfishes, and goosefishes discussed here hold certain features in common. All are bottomliving forms with depressed head areas and broad gapes, and all eat large food items: fishes and/or crabs. All have developed structural specializations in association with this diet. The three groups are at most distantly related, and their feeding specializations are different and have evolved from different bases. In flatheads the combination of large food items and depressed head regions seems to have led to the separation of the two halves of the pelvic girdle, a feature in which they differ from their scorpaenoid relatives. Toadfish peculiarities associated with feeding are various but most notable in those that pass crabs they eat through the gape and into the mouth. Goosefish feeding is centered around the use of a lure to attract prey to within striking distance. The three fish groups are discussed separately, but their feeding structures are compared to one another in the final section of the paper.

\section{Introduction}

The three groups under consideration here (Fig. 1) are the flatheads (family Platycephalidae, order Scorpaeniformes), toadfishes (genera Opsanus and Batrachoides, order Batrachoidiformes), and goosefishes (family Lophiidae, order Lophiiformes). These groups are distantly related to one another but show certain general features in common. All spend considerable time in contact with the bottom; all have depressed head areas; and all eat large food items - fish and/or crabs. The modifications in feeding-related structures in the three groups are dealt with separatedly and in the context of close relatives. In the flatheads, the Ieast specialized of the three, the discussion centers on the separation of the two halves of the pelvic girdle. Though such a separation also occurs in the other two groups, its development is most satisfactorily traced in the flatheads. In the toadfishes a variety of modifications seem to be associated with feeding. In the goosefishes the modifications are also various, but all appear to be centered around the use of a lure to attract prey.

\section{Flatheads (Fig. 1a)}

The family Platycephalidae contains about 12 , mostly Indo-Pacific genera. The food of the bestknown genus, Platycephalus, consists of fishes and crabs, and Marais (1984) remarks on the large size of a fish taken from a Platycephalus stomach.

Aside from the flattened head areas, flatheads appear to be quite normal scorpaeniform fishes. The two eyes are rather close together on the top of the head but the eye pupils are near the base of the large eyeballs and presumably provide vision to the 
side of the fish. The two nostrils on each side are on the upper surface of the head (unlike those of toadfishes). The lateral expansion of the head at the level of the mouth provides a very wide gape. The lower jaw is flat below and projects somewhat beyond the upper. The dentition is of a generalized type, with bands of fixed, conical teeth on the premaxillae, vomer, palatines, mandible, and pharyngeals. The genus Ratabulus is exceptional among platycephalide genera in having depressible teeth (Knapp personal communication). The gill openings extend far forward under the throat, and it seems clear that Platycephalus (unlike Opsanus, see below) can lower the anterior end of the hyoid arches relative to the mandible, for the sternohyoideus muscle is attached to a well-developed urohyal bone, as usual in fishes.

The most notable specialization of platycephalids, and one in which they differ not only from their scorpaeniform relatives but from most higher teleosts, is the structure of their pelvic girdles (Fig. 2a).

The two halves of the pelvic girdle, examined in members of the genera Cociella, Grammoplites,

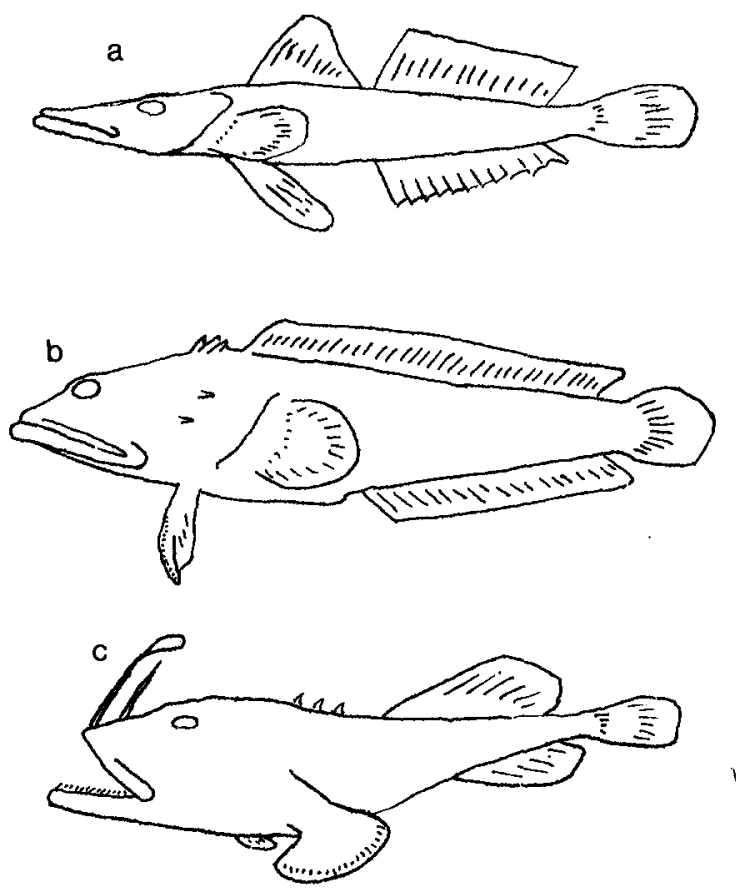

Fig. 1. Sketch of a typical: $\mathrm{a}=$ flathead, $\mathrm{b}=$ toadfish, and $\mathrm{c}=$ goosefish.
Onigocia, Platycephalus, Rogadius, Sorsogonia, Suggrundus and Thysanophrys, are not firmly united posteriorly but merely overlap slightly if at all. This flexibility in the attachment of the two sides of the girdlis is interpreted here as a method of accomodating large food items in the stomach directly above the girdle.

The closest relatives of the Platycephalidae are the Bembridae, and the two groups are often combined into a single family (e.g. Masuda et al. 1984). The platycephalids have more flattened head regions than the bembrids, longer anal fins without anal spines, and pelvic fins that are farther back under the body and more widely spaced, but the most striking difference between the two families is in pelvic girdle structure. Bembrids (Fig. 2b) have quite normal, scorpaeniform-type pelvic girdles, with the two halves firmly united posteriorly. According to the hypothesis advanced here the platycephalids should eat larger food items than the bembrids. That the platycephalids eat large items
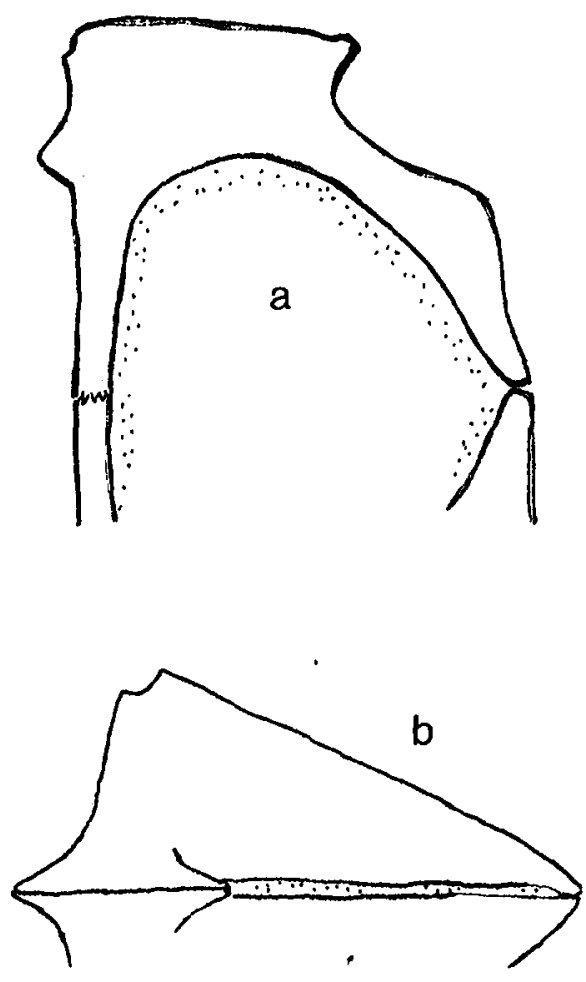

Fig. 2. Left half of the pelvic girdle from below of $a=$ Platycephalus indicus, and of whole girdle of $\mathrm{b}=$ Parabembras curtus. 
has been noted above. Unfortunately, the food of bembrids appear to be unknown, and the stomachs of the bembrids opened were empty, but supporting evidence for the idea that platycephalids eat larger items than bembrids exists in the more capacious stomachs of platycephalis (Fig. 3).

The separated halves of the pelvic girdle in the flatheads, and in the toadfishes and goosefishes, represents a reversal in the usual course of teleostean evolution, where the two halves are movably articulated with one another in lower teleosts but usually firmly united at the percoid-scorpaenoid level (Stiassny \& Moore 1992). The separation is discussed in flatheads because there, unlike the other two groups, it can be compared with the united girdle halves in the closely-related bembrids. That the separation of the two halves of the pelvic girdle is not caused by the flattening of the head alone is suggested by the fact that in the very similarly-shaped dragonets (Callionymus), which eat smaller food items, the two halves of the pelvic girdle are united, as usual in higher teleosts.

\section{Toadfishes (Fig. 1b)}

In a number of features associated with feeding the toadfishes (Opsanus and Batrachoides) and their allies among the batrachoidiform fishes are unusual, and in one of them, the hinge between the lateral ethmoid and the maxilla (Fig. 4), unique among te-

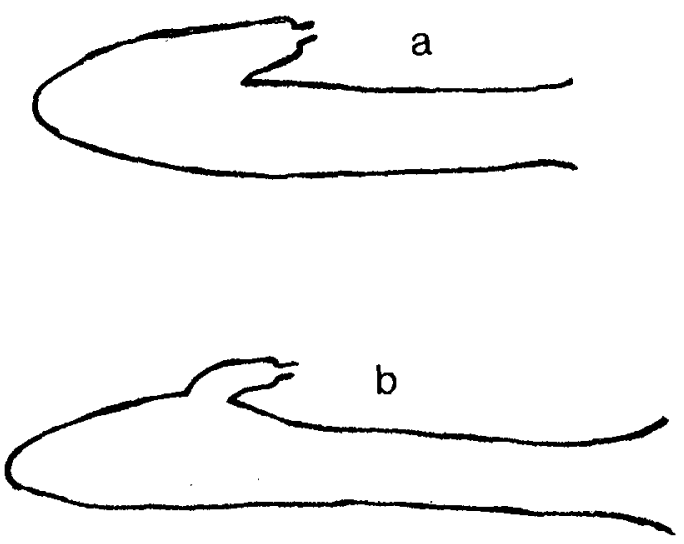

Fig. 3. Outline of esophagus and stomach: $\mathrm{a}=$ Platycephalus indicus, $\mathrm{b}=$ Parabembras curtus. leosts. Though genera related to the toadfishes feed on a variety of things from sea urchins (Hoffman \& Robertson 1983) to fishes (Lane 1967), Opsanus (Schwartz \& Dutcher 1963) and Batrachoides (Collette \& Russo 1981) specialize in crabs.

Toadfishes are normally in contact with the bottom. as are the crabs. The somewhat forwardly directed eyes and the anterior nostrils at the ends of horizontal tubes that project anteriorly to above the upper jaw are probably related to the fact that their major food items are directly in front of them. To capture their larger prey toadfishes use a camouflage-and-ambush technique, and they must swim directly forward over the substrate to capture such items. Their mouth structures differ in several respects from bottom-resting fishes such as the goosefishes (Lophidae, see below) which seize prey swimming overhead, or the goatfishes (Mullidae) which swim over their benthic food below them. One of the toadfish differences is in the way that the mandible is lowered to open the mouth. To obtain such lowering while the mandible is maintained in a more or less horizontal position just above the substrate, there must be a slight raising of the head relative to the rest of the body. In toadfishes there is no joint-like arrangement between the head and the vertebral column. Indeed, the skull is effectively continued into the body by the firm attachment of the neural arch of the first vertebra to the back of the skull. Raising of the front end of the body is probably accomplished by lowering of the pelvic fins (as in Fig. Ib) against the substrate. These fins

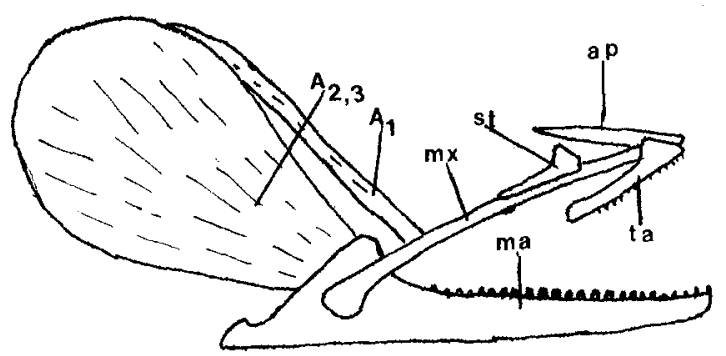

Fig. 4. Jaws and jaw musculature of Opsanus beta: $\mathrm{A}_{1}$ and $\mathrm{A}_{2.3}=$ sections of the $\mathrm{m}$. adductor mandibulae (ap = ascending process of the premaxilla, $\mathrm{ma}=$ mandible, $\mathrm{mx}=$ maxilla, $\mathrm{st}=$ hinged $\mathrm{strut}$ between the ethmoid of the skull and the maxilla, and ta $=$ toothed arm of the premaxilla). 
are well forward under the body and have a fibrous pad along the front border of the leading ray.

If the front of the lower jaw is pushed forward over the substrate, the already somewhat prognathous mandible extends even farther ahead of the upper jaw when the head is raised. This discrepancy is probably counteracted for purposes of an initial bite by protrusion of the premaxillae. The potential problem here is somewhat alleviated by the fact that toadfishes do not open their mouths very far in a vertical direction (see below).

As indicated by the large parts of crab carapace often found in toadfish stomachs, they take the whole animal into the mouth. In this method of feeding they differ from such small-mouthed crabeaters as the filefishes (Monacanthus). Filefishes attack by first plucking off the eyestalks, after which they dismember the rest of the animal piece by piece (personal observation).

The gape and mouth of toadfishes are very wide but shallow. That toadfishes never lower their mandibles very far is indicated by the restriction in downward movement by the functionally associated maxillae. One indication of this restriction is the small amount of the maxillary shaft that is free from the skin of the cheek. Another is the posterior insertion of the $A_{i b}$ section of the $m$. adductor mandibulae along the maxillary shaft (Gosline 1993).

As to gape width, the articulations between the backs of the mandible and the suspensoris are wide apart in the broad-headed toadfishes and can be spread even farther apart by contraction of the levator arcus palatini muscles, as usual in fishes. Where toadfishes differ from other wide-headed fishes is that the width of the gape is maintained or even increased when the mouth opens. The cause of this lies in the relationship between the lateral ends of the maxillae and the mandible.

When the mouth is opened in fishes with the usual extensive mandibular lowering, the lateral ends of the maxillae swing down closer to one another along the sides of the mandible which decreases in width anteriorly. In toadfishes narrowing between the lateral ends of the maxillae as the mouth opens is prevented in part by the fact that the mandible and maxillae are never lowered very far and in part by the nature of the lower jaw, the two sides of which flare outward in the coronoid areas (Fig. 5). The most widely flaring parts of these coronoid areas remain just behind the maxillary attachments as the mouth is opened. As a result the width of the gape is maintained as the mouth opens and may even be widened a little if the widest parts of the coromoid areas shift somewhat forward relative to the lateral ends of the maxillae.

As these lateral ends move down and forward the proximal parts of the maxillae are propped from above, not by the usual palatine prong of higher teleosts, but by a hinged strut (Fig. 4) between the outer border of the maxillary shaft and the ethmoid area of the skull. This strut, considered by Gosline (1993) to be a part of the lateral ethmoid, may well be a lacrimal bone, but if so it is the only ossified member of the circumorbital series present in the batrachiform (or lophiiform) fishes.

The forward movement of the outer ends of the maxillae when the mouth opens results in some twisting of the maxillary shaft. The twisting of the proximal end of the maxillae results in premaxillary protrusion, as usual in higher teleostean fishes. However, batrachoidiform fishes differ from most other higher teleosts in having a hinge between the ascending process and the toothed limb of the premaxilla. The inner head of the maxilla abuts against the forward base of the toothed limb. Thus, when the maxillary shaft twists it causes the toothed limb to swing outward and forward relative to the ascending process as well as causing the ascending process to slide forward over the skull. The result is a nearly transverse border at the front of the protruded premaxillae.

The mouth cavity of toadfishes, like their gape, is broad but shallow. It differs, especially from the mouth cavity of deep-bodied fishes, in that the front of the hyoid arch system (the 'tongue' area) can be lowered only slightly relative to the mandible. The main force exerted by the front of the hyoid arch system (Fig. 6) seems to be upward against the roof of the mouth rather than downward to enlarge the mouth cavity. Such upward movement raises the front of the hyoid arch system with its abruptly downturned glossohyal against the mouth roof just behind the arc of palatine-vomerine teeth and pre- 


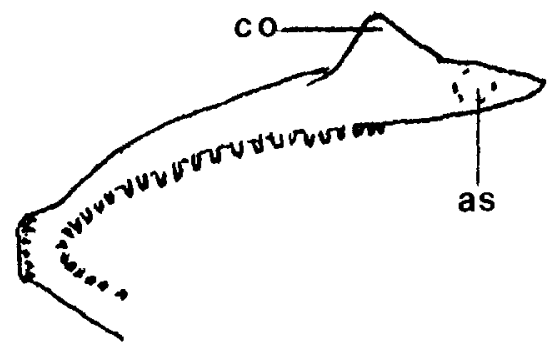

Fig. 5. Right half of lower jaw of Opsanus tau from above (as = articular socket, and $c o=$ coronoid area).

sumably holds prey items in position during the main bite.

This supposition about hyoid arch movement is based on the structures involved. Much of the space between the two halves of the mandible is covered ventrally (Fig. 6) by the large protractor hyoidei (Winterbottom 1974). This pair of muscles extends forward from about midway along the hyoid arches to the symphysial area of the mandible. The members of the pair meet and are attached to one another midventrally below the front of the hyoid arch system and thus limit its lowering relative to the mandible. Contraction of the pair apparently moves the forward part of the hyoid arch system forward and somewhat upward relative to the mandible. Furthermore, in fishes where there is considerable lowering of the front of the hyoid arch system, the urohyal bone (Kusaka 1976) is a principal agent in the process of lowering and is accomplished by contraction of the sternohyoideus muscles (Fig. 6) to the urohyal. In toadfishes the urohyal is greatly reduced with little or no muscle attachment to it. Instead the sternohyoidus muscles of toadfishes insert on the hypohyals, and their contraction appears to exert little downward force.

The bite in toadfishes has three separate but coordinated components. The anteriormost is a transvers, grasping bit, the width of which is much shorter than the gape. It is between the protruded premaxillaries above and the front teeth of the mandible. The hinged premaxillaries are not strongly constructed and their bite can only deter prey items from escaping until they are passed back to the main bite in the mouth. Once in the mouth the prey is subjected to a powerful crushing-shearing bite between an arc of peg-like teeth on the mandible and an arc of similar teeth just behind on the vomer and palatines. The strength of this bite is attested by various authors who have been bitten by toadfishes, e.g., Gudger (1910). The blunt teeth of this bite have the same configuration even when first appearing in open tooth sockets. The three bones of the lower jaw are closely knit. The large $\mathrm{A}_{2,3}$ section of the m. adductor mandibulae (Fig. 4) inserts directly on the inside of the coronoid area of the mandible. (In toadfishes the usual separate $\mathrm{W}_{\mathrm{w}}$ section on the mandible is absent). The teeth on the palatines extend far back and appear to represent a shearing section of the bite.

After the crushing and dismembering of large prey items by the main bite just described the pieces are moved back to the pharyngeal bite. Here, the teeth, unlike those of the main bite, are relatively small, conical, and sharp-pointed. They appear to be concerned with mastication. The lower pharyngeals and separate, as usual, but are supported by the ceratobranchials of the fourth gill arch. This arch, usually a part of the respiratory system, has no gill filaments in batrachoidiform (or liphiiform) fishes (Regan 1912) and is embedded in the lining of the mouth cavity.

In the same family as the toadfishes, the midshipmen (Porichthys) differ in dentition from the other genera of the family examined (Batrachoides, $B a$ trachomoeus, Coryzichthys, Opsanus, and Thalas-

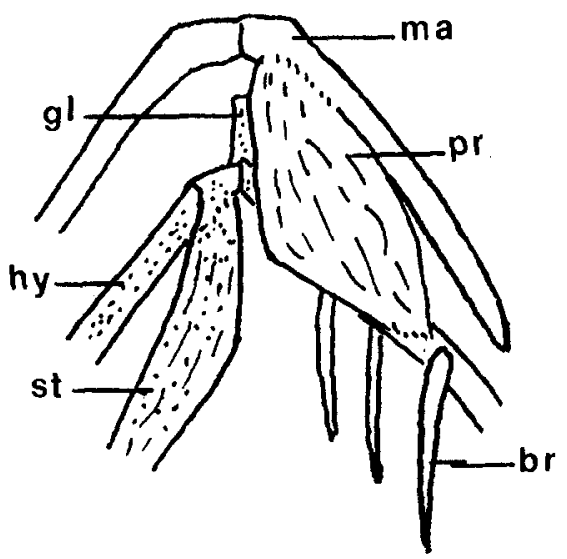

Fig. 6. Chin area of the lower jaw of Opsanus tau from below, with the $\mathrm{m}$. protractor hyoidei and the branchiostegal rays of the right side removed $(\mathrm{br}=$ branchiostegal ray, $\mathrm{gl}=$ glossohyal, hy = hyoid arch, $\mathrm{ma}=$ mandible, $\mathrm{pr}=\mathrm{m}$. protractor hyoidei, and $\mathrm{st}=$ m. sternohyoideus). 
sophryne). Though Porichthys has the other mouth characters described above for toadfishes, the teeth are sharp-pointed and differently arranged. There is no continuous arc of teeth across the front of the vomer. Instead, the anterior border of the vomer is indented, and there are one or two canine teeth on each side of the indentation. Indeed, the whole vomerine area of the skull of midshipmen is somewhat different from that of toadfishes (Starks 1926, fig. $52,63)$.

These structural differences between midshipmen and toadfishes appear to reflect differences in the food and feeding of the two groups. The Pacific Porichthys myriaster is said to be widely omnivorous (Fitch \& Lavenberg 1975). Lane (1967, Table 5) provides an extensive list of food items found in the stomachs of the Atlantic $P$. porossissimus ( $=$ P. plectrodon). In neither species are crabs an important component. In the Atlantic species, mysid crustacea and small anchovies are the main food source. That the items eaten by midshipmen are smaller then those taken by toadfishes is also indicated be the longer gill rakers of midshipmen, which are nocturnal feeders (Lane 1967). How midshipmen feed has not been observed, but the food eaten suggests that they swim over the bottom at night.

\section{Goosefishes (Fig. 1c)}

Of the three groups discussed here goosefishes have much the most specialized feeding method. Like other members of the Lophiiformes, e.g., the anglerfishes, they use a lure to attract fishes swimming overhead to within striking distance. This lure is a movable anterior dorsal spine to which a fleshy flap (the esca) is attached. This is a visual lure depending on light for its effectiveneness. However, goosefishes occur in fairly deep water with relatively little light penetration (Caruso 1983), and it seems reasonable to wonder whether there the lure is used in a somewhat different way. In any event a goosefish either grabs the prey attracted by the lure or the prey swims away, for the goosefish is not an efficient pursuer.

Goosefishes lie flat against the bottom. When the prey is attracted to within striking distance they abruptly raise the front of the body to meet it (see observations on Lophioides by Chave \& Mundy 1994). This upward movement is brought about through the highly specialized paired fin structures. The paired fins themselves are not lowered when the fish lunges upward; rather they continue to lie flat against the substrate, and it is the supports for the fins that are lowered - the pectoral actinosts and the pelvic girdle. The highly peculiar actinosts of Lophius and other liphiiform fishes (Starks 1930, fig. 38) have a jointed articulation with the pectoral fin. The pelvic girdle of Lophius (and presumably other lophiiform fishes) appears to be unique in the musculature that enables the posterior border of the pelvic girdle to be lowered (Grenholm 1923, fig. 150).

The prey is grasped between the sharp, posteriorly directed teeth on the strongly constructed but protrusibile premaxillae and similar teeth on the mandible. This is the only bite the fish has. Once seized, the prey is merely passed back whole to the stomach via the pharyngeal dentition, which is similar to that on the jaws. (A $117 \mathrm{~mm}$ Lophius litulon examined has an almost undamaged gobioid fish about $95 \mathrm{~mm}$ long curled up in its stomach as well as another smaller fish.) The only teeth on the vomer are a few rudimentary knobs, and there are none on the palatines. The separate lower pharyngeals are entirely ahead of the upper pharyngeals. They are free at both ends with longitudinal musculature attached to their under surfaces and can apparently be moved back within the mouth. The upper pharyngeal teeth are just ahead of the esophagus.

\section{Discussion}

A large and varied group of fishes has 'flattened' itself against the substrate - skates among elasmobranchs and, among bony fishes, callionymids, hoplichthyids, pegasids, ogcocephalids, and the three groups discussed here as well as, in a different way, the flatfishes. Presumably this flattening provides a way of fading into the bottom for defensive and sometimes, for attack, purposes.

Excluding flatfishes, such bony fish groups may be divided into those forms that feed on organisms 
within the substrate and those that feed on animals on or slightly above the bottom. The former group seems in general to eat smaller items and have smaller mouths that can be protruded downward from the under surface of the head. The flatheads, toadfishes, and goosefishes all eat items on or slightly above the substrate, and their food consists primarily of relatively large items. This combination of depressed head area and large food items is accompanied by a number of specializations associated with feeding. For purposes of discussion these can be divided between the various steps of the feeding process. The first of these is the capture of prey. Here the goosefishes are much the most specialized of the three groups, with a lure system to attract the fish prey to within striking distance. The other goosefish modifications are all associated with this feeding style. A second feeding step is to get the seized prey into the mouth. Here, the toadfishes are the most specialized in their modifications for maintaining a broad gape to permit the passage of whole crabs into the mouth. Once into the mouth goosefishes and toadfishes use very different methods for manipulating their prey. Goosefishes simply pass the whole fish into the stomach whereas toadfishes dismember and crush the crabs they eat. A further step in feeding is the provision for room in the stomach for the food passes to it. Such accomodation is provided in all three of these flatheaded groups by the ability to expand the stomach in a ventral direction. This accomodation is provided by the separation of the two halves of the pelvic girdle which are usually firmly united in higher teleost. A final step in the feeding process is. of course, the digestion of the stomach contents, but this is primarily a physiological matter beyond the scope of the present paper.

\section{Acknowledgements}

Specimens examined are in the collections of the Musuem of Zoology at the University of Michigan. I wish to thank Leslie Knapp for literature on the flatheads, Frank Schwartz for references on the toadfishes, and Gerald Smith for comments on the original toadfish manuscript.

\section{References cited}

Caruso. J.H. 1983. The systematics and distribution of the lophiid anglerfishes: II. Revision of the genera Liphiomus and Lophius. Copeia 1983: 11-30.

Chave. E.H. \& B.C. Mundy. 1994. Deep-sea benthic fish of the Hawaiian Archipelago, Cross Seamount. and Johnston Atoll. Pacific Science 48: 367-407.

Collette, B.B. \& J.L. Russo. 1981. A revision of the scaly toadtishes, genus Batrachoides with descriptions of two new species from the eastern Pacific. Bull. Mar. Sci. 31: 197-233.

Fitch.J.E. \& R.J. Lavenberg. 1975. Tidepool and nearshore fishes of California. Calif. Nat. Hist. Guides 38.156 pp.

Gosline. W.A. 1993. A survey of upper jaw musculature in higher teleostean fishes. Occ. Pap. Mus. Zool.. Univ. Michigan 724: $1-26$

Grenholm. A. 1923. Studien über die Flossenmuskulatur der Teleostier. Uppsala Univ. Arsskr. Mat. Nat. 2: 1-293.

Gudger, E.W. 1910. Habits and life history of the toadfish (Opsanus tau.). Bull. Bur. Fish. 28: 1071-1109.

Hoffman, S.G. \& D.R. Robertson. 1983. Foraging and reproduction of two Caribbean reef toadfishes (Batrachoididae). Bull. Mar. Sci. 33: 919-927.

Kusaka, T. 1976. The urohyal in fishes. University of Tokyo Press, Tokyo. 320 pp.

Lane. E.D. 1967. A study of the Atlantic midshipman, Porichthys porossissimus, in the vicinity of Port Aransas. Texas. Contrib. Mar. Sci. 12: 1-53.

Marais, J.F.K. 1984. Feeding ecology of major carnivorous fish from eastern Cape estuaries. S. Afr. J. Zool. 19: 210-223.

Masuda, H., K. Amaoka, C. Araga, T. Uyeno \& T. Yoshino (ed.) 1984. The fishes of the Japanese Archipelago, 2 vol., Tokai University Press, Tokyo. 437 pp.

Regan, C.T. 1912. The elassification of the teleostean fishes of the order Pediculati. Ann. Mag. Nat. Hist. (ser. 8) 9:277-289.

Schwartz, F.J. \& B.D. Dutcher. 1963. Age. growth and food of the oyster toadfish near Solomons, Maryland. Trans. Amer. Fish. Soc. 92: 170-173.

Starks. E.C. 1926. Bones of the ethmoid region of the fish skull. Stanford Univ. Publ. Biol. Sci. 4: 139-338

Starks. E.C. 1930. The primary shoulder girdle of the bony tishes. Stanford Univ. Publ. Biol. Sci. 6: 149-239.

Stiassny, M.L.J. \& J. Moore. 1992. A review of the pelvic girdle of acanthomorph fishes, with comments on hypotheses of acanthomorph intrarelationships. Zool. J. Linnean Soc. 103: 209242.

Winterbottom. R. 1974. A descriptive synonymy of the striated muscles of the Teleostei. Proc. Acad. Nat. Sci. Philadelphia 125: $225-317$. 